\title{
Atividade antiproliferativa e mutagênica dos extratos aquosos de Baccharis trimera (Less.) A. P. de Candolle e Baccharis articulata (Lam.) Pers. (Asteraceae) sobre o sistema teste de Allium cepa
}

FACHINETTO, J.M.; TEDESCO, S.B. *

Universidade Federal de Santa Maria (UFSM), Departamento de Biologia, Av. Roraima, $n^{\circ} 1000$ - Cidade Universitária, CEP:97119900, Santa Maria-Brasil. “stedesco@smail.ufsm.br

\begin{abstract}
RESUMO: As espécies medicinais Baccharis trimera e Baccharis articulata, nativas no sul do Brasil, são muito utilizadas na medicina popular. Este estudo objetivou avaliar o potencial efeito citotóxico destas infusões sobre o ciclo celular de Allium cepa. Ramos de duas populações de cada espécie coletados durante os estádios vegetativo e reprodutivo (floração) foram usados para preparar infusões em duas concentrações: $15 \mathrm{mg} \mathrm{mL}^{-1}$ e $75 \mathrm{mg} \mathrm{mL}^{-1}$. Células das pontas de raízes Allium cepa são usadas como sistema teste in vivo. Foram preparadas lâminas através da técnica de esmagamento. As células foram analisadas em todo o ciclo celular de $A$. cepa, totalizando 4000 células para cada grupo de bulbos. O índice mitótico (IM) foi calculado e realizado análise estatística através do teste Qui-quadrado $\left(c^{2}=0,05\right)$. Os resultados mostraram que as infusões de $B$. trimera nas duas populações causaram redução do IM em relação ao controle, mas não entre as concentrações, em ambos estádios utilizados. Os extratos de $B$. articulata também apresentaram redução do IM em relação ao controle, sendo que uma das populações apresentou diferença do IM entre as concentrações nos dois estádios, o que não ocorreu na outra população. Com relação à presença de células com aberrações cromossômicas, esta ocorreu em todas as populações estudadas. Os resultados indicaram que os extratos dessas espécies apresentaram efeito antiproliferativo e mutagênico para as concentrações estudadas, não possuindo diferença nesses efeitos quanto ao estádio de desenvolvimento das plantas.
\end{abstract}

Palavras-chave: plantas medicinais, mutagênese, antiproliferativo

\begin{abstract}
Antiproliferative and mutagenic activities of aqueous extract of Baccharis trimera (Less.) A. P. de Candolle and Baccharis articulata (Lam.) Pers. (Asteraceae) on the Allium cepa test system. The medicinal species Baccharis trimera and Baccharis articulata, which are native to the south of Brazil, are extensively used in popular medicine. This study aimed to evaluate the potential cytotoxic effect of these infusions on the cell cycle of Allium cepa. Branches of two populations of each species collected during the vegetative and reproductive (flowering) stages were used to prepare infusions at two concentrations: $15 \mathrm{mg} \mathrm{mL}^{-1}$ and $75 \mathrm{mg}$ $\mathrm{mL}^{-1}$. Onion (Allium cepa) root-tip cells were used as an in vivo test system. Slides were prepared through smashing technique. Cells were analyzed throughout $A$. cepa cell cycle, totaling 4000 cells for each group of bulbs. The mitotic index (MI) was calculated, and the statistical analysis performed using the Chi-square test $\left(\mathrm{c}^{2}=0.05\right)$. Results showed that $B$. trimera infusions caused $\mathrm{MI}$ reduction in both populations, compared with control, but not between concentrations in both used stages. Similarly, B. articulata extracts led to Ml reduction, compared with control, and one of the populations had MI difference between concentrations in both stages. Cells with chromosome aberrations were present in all studied populations. Results indicated that the extract of both species showed antiproliferative and mutagenic effects at the studied concentrations; however, no difference was found concerning plant development stage.
\end{abstract}

Key words: medicinal plants, mutagenesis, antiproliferative

Recebido para publicação em 26/05/2008

Aceito para publicação em 10/06/2009

Rev. Bras. PI. Med., Botucatu, v.11, n.4, p.360-367, 2009. 


\section{INTRODUÇÃO}

As plantas medicinais são muito utilizadas na medicina popular, sendo algumas vezes, a única fonte de medicação que a população tem acesso. Entre as plantas com potencial medicinal, estão as espécies da família Asteraceae, como B. trimera e $B$. articulata, nativas no sul do Brasil.

B. trimera, conhecida como carqueja, carqueja-amargosa, é um arbusto pequeno, dióico, ramificado, com ramos sem folhas, trialados, com alas interrompidas alternadamente, membranosas a levemente coriáceas (Simões et al., 1986). As partes aéreas desta planta são usadas internamente, como estomáquica, anti-reumática, anti-helmíntica, em problemas do fígado, em diabetes e em casos de gastroenterite, anorexia, gripe e resfriado; externamente, no tratamento de feridas e ulcerações (Simões et al., 1986). Pode ser encontrada em cápsulas para emagrecimento, em associação com outras espécies. O óleo essencial é composto principalmente por carquejol, acetato de carquejila e sesquiterpenos, além de palustrol, $\alpha$ e $\beta$-pineno, trans- $\alpha$-ocimeno e espatulenol entre outros (Siqueira et al., 1985; Santos et al., 1988; Sousa et al.,1991). Também apresenta flavonóides como a quercetina, luteolina, nepetina, apigenina, rutina, hispidulina (Soicke \& LengPeschlow, 1987; Di Stasi et al., 1988), eupatorina, cirsimaritina, cirsiliol, apigeina, genkwanina e eriodictiol (Kuroyanagi et al., 1985; De Mello \& Petrovic, 2000), diterpenos, compostos tânicos e saponinas (Castro et al., 1999; Jarvis et al., 1991; Zdero et al., 1991).

$B$. articulata, conhecida como carquejinha, carqueja-doce, difere-se de $B$. trimera por possuir seus ramos bialados, verde-acinzentados. Suas partes aéreas são usadas internamente, como digestiva, diurética, amarga, tônica, antifebril e no combate de dispepsias atônicas, debilidade orgânica e anemia. Na Argentina, acredita-se que tenha atividade no tratamento de impotência sexual masculina e de esterilidade feminina. No Paraguai é utilizada como anti-hipertensiva (Simões et al., 1986). Possui, segundo a literatura, basicamente flavonóides, taninos e terpenos, sendo os terpenóides os compostos de maior número e entre eles os triterpenos (Siqueira, 1988). Dois diterpenos do tipo neoclerodano foram determinados a aticulina I e acetato de articulina (Simões et al., 1986). A composição química compreende o ácido crisosaponico, ácido resínico, ácido oleanólico; terpeno lupeol e flavonóides como santonina, absintina, luteolina, quercetina, genkwanina, acacetina, 7,4-dimetil-apigenina, circimaritina, salvigenina, jaceidina, jaceosidina, chondrillasterol (Alonso, 1998). Nas flores foram encontrados um diterpeno furânico, o barticulidiol; um diterpeno clerodano, a bachotricuneatina A (Gianello \&
Giordano, 1982); além de um diéster malonato (Alonso, 1998). Em seu óleo essencial foram detectados $\beta$-cariofileno, nerodiol, cis-cariofileno, $\gamma$ elemeno, $\beta$-guaieno, $\delta$-candieno, $\alpha$-pineno e aromadendro (Alonso, 1998), além de $\beta$-pineno, limoneno, espatulenol (Simões-Pires et al., 2002).

Estima-se que mais de 60 e $75 \%$ dos fármacos utilizados atualmente no tratamento do câncer e em doenças infecciosas, respectivamente, são derivados de fontes naturais (Newman et al., 2003), sendo de grande relevância, estudos de toxicidade e mutagenicidade, pois contribuem para utilização segura e eficaz. O índice mitótico e índice de replicação são usados como indicadores de proliferação adequada das células (Gadano et al., 2002), o que pode ser medido através do sistema teste vegetal de Allium cepa. O método da aberração cromossômica em raízes de Allium é validado pelo Programa Internacional de Segurança Química (IPCS, WHO) e o Programa Ambiental das Nações Unidas (UNEP) (Cabrera \& Rodriguez, 1999; Silva et al., 2004). Além disso, estudos utilizando esse sistema teste juntamente com o de mamíferos têm sido realizados, demonstrando que os resultados obtidos são similares (Teixeira et al., 2003; Camparoto et al., 2002; Vicentini et al., 2001).

O objetivo deste estudo foi avaliar os efeitos dos extratos aquosos (chás) de $B$. trimera e $B$. articulata, obtidos segundo sua utilização popular, através de plantas nos diferentes estádios de crescimento das espécies, vegetativo e reprodutivo (floração), sob o sistema vegetal de Allium cepa.

\section{MATERIAL E MÉTODO}

\section{Coleta das plantas}

Ramos de duas populações de $B$. trimera (Jardim Botânico - Universidade Federal de Santa Maria (UFSM), Santa Maria (População 1); e São Pedro do Sul (População 2) e de B. articulata (Jardim Botânico - UFSM (População 1) e UFSM (População 2) foram coletados no Rio Grande do Sul, Brasil. Cada população foi coletada duas vezes, uma durante 0 período vegetativo e outra durante o reprodutivo (floração). De cada população, colocou-se uma amostra testemunha no herbário SMDB (Santa Maria Departamento de Biologia), da UFSM, sob número de registro: 10005 (B. trimera População 1), 10081 (B. trimera População 2), 10004 (B. articulata população1) 10006 (B. articulata população 2). As plantas foram identificadas pela Profa Draㅡ Thais do Canto-Dorow.

\section{Preparo das infusões}

Os extratos aquosos (chás) dos ramos recém coletados de cada população em cada estádio 
coletado de $B$. trimera e $B$. articulata foram preparados por decocção em 2 concentrações: $15 \mathrm{mg} \mathrm{mL}^{-1}$ e 75 $\mathrm{mg} \mathrm{mL}^{-1}$. A concentração de $15 \mathrm{mg} \mathrm{mL}^{-1}$ é usualmente utilizada para preparar o chá medicinal, segundo a Farmacopéia dos Estados Unidos do Brasil (1959). Utilizaram-se 3 grupos de 4 bulbos de Allium cepa para cada população em cada estádio coletado de $B$. trimera e $B$. articulata, cada grupo equivalendo a uma das concentrações. Todos os bulbos foram colocados em água destilada para enraizarem, após o enraizamento, os mesmos foram transferidos para os extratos que estavam em temperatura ambiente permanecendo por 24 horas, (um grupo permaneceu em água como controle). A seguir, foram coletadas as radículas com aproximadamente $5-10 \mathrm{~mm}$ de comprimento e fixadas em etanol:ácido acético (3:1) por $24 \mathrm{~h}$ e mantidas em etanol $70 \%$ e conservadas sob refrigeração até o uso.

\section{Efeitos das infusões sobre o ciclo celular de Allium cepa}

Foram feitas em média 5 lâminas por bulbo de cada tratamento e controle de cada população coletada. No preparo das lâminas, as radículas foram hidrolisadas em $\mathrm{HCl} 1 \mathrm{~N}$ por 5 minutos. Foram, então, lavadas em água destilada e coradas com orceína acética $2 \%$. A região meristemática das radículas foi fragmentada com o auxílio de agulhas histológicas, e a lamínula colocada sobre o material (Guerra \& Souza, 2002). Foi feita a análise de 1000 células de cada bulbo, totalizando 4000 células por grupo de bulbos. As lâminas foram avaliadas com auxílio de microscópio óptico com a objetiva de 40X, observandose as células em interfase e divisão celular (mitose) para calcular o Índice Mitótico (IM), bem como, a ocorrência de aberrações celulares, como presença de pontes, cromossomos retardatários, micronúcleos, células binucleadas, entre outras.

\section{Análise estatística}

A análise estatística dos dados foi realizada pelo teste $\chi^{2}$ com nível de probabilidade $<0,05$ através do programa BioEstat 3.0 (Ayres, 2003).

\section{RESULTADO}

Os resultados obtidos neste trabalho estão apresentados nas Tabelas 1 e 2.

$\mathrm{Na}$ Tabela 1, são apresentados o número total de células analisadas, o número de células que foram observadas em interfase e em diferentes fases da divisão celular durante o ciclo celular de Allium cepa, bem como os valores do índice mitótico. Para a espécie $B$. trimera, é possível observar na Tabela 1 , que para ambas as populações estudadas, houve uma inibição da divisão celular na concentração usual de (15 mg mL-1) com relação ao controle (população 1 $\chi^{2}=121,3$ e 236,7 , população $2 \chi^{2}=211$ e 236,7$)$. Os valores de IM diferiram entre os tratamentos somente na população $1\left(\chi^{2}=70,9\right)$, quando se testou os extratos obtidos com as plantas no estádio vegetativo.

A espécie $B$. articulata também apresentou redução dos valores de IM, já na concentração usual em ambas as populações (população $1 \chi^{2}=133,4 \mathrm{e}$ 49,9 , população $2 \chi^{2}=101,2$ e 54,1 ). No entanto, as concentrações diferiram significativamente entre si na população $1\left(\chi^{2}=10,6\right.$ e 38,9), não apresentando diferença na população $2\left(\chi^{2}=0,6\right.$ e 2,6$)$.

$\mathrm{Na}$ Tabela 2, são apresentados o número total de células analisadas, bem como o número de células que possuíam aberrações cromossômicas e o total de aberrações celulares.

Os extratos de $B$. trimera e $B$. articulata apresentaram três tipos de aberrações celulares: células binucleadas (Figura 1a), células micronucleadas (Figura 1b) e pontes em anáfase e telófase (Figura 1c). As aberrações foram encontradas em ambos os tratamentos e estádios de desenvolvimento para todas as populações estudadas.

Na população 1 de $B$. trimera, o número de aberrações celulares observado nas células de Allium cepa diferiu do controle em ambas as concentrações $\left(\chi^{2}=30,11,42,2,28,09\right.$ e 26,08$)$, mas não diferiu entre os tratamentos $\left(\chi^{2}=2,01\right.$ e 0,7$)$. Já a população 2 , os tratamentos também diferiram entre si $\left(\chi^{2}=43,7\right.$ e 37,72).

B. articulata, na população 1 , quando utilizado os extratos obtidos das plantas no estádio reprodutivo, o número de aberrações celulares diferiu do controle somente na concentração usual $\left(\chi^{2}=\right.$ $32,1)$, e quando utilizados os extratos das plantas no estádio vegetativo, ambas as concentrações diferiram do controle $\left(\chi^{2}=19,04\right.$ e 9,01). Já na população 2 , para os extratos obtidos das plantas no estádio reprodutivo, o número de aberrações celulares foi diferente do controle $\left(\chi^{2}=21,05\right.$ e 26,08$)$, mas não diferiram entre si $\left(\chi^{2}=0,5\right)$, e para os extratos das plantas no estádio vegetativo, as concentrações diferiram do controle $\left(\chi^{2}=43,2\right.$ e 21,05$)$ e entre si $\left(\chi^{2}=\right.$ $7,6)$.

\section{DISCUSSÃO}

Apesar da família Compositae (Asteraceae) compreender algumas das mais antigas e mais valorizadas plantas medicinais (Paulsen, 2002), diferentes gêneros desta família apresentam compostos tóxicos como ácidos tanínicos, hidrociânicos, fórmicos e málicos, rutina e furfural (Duke, 2000).

Utilizou-se para a realização deste trabalho o sistema teste vegetal de Allium cepa para avaliar os efeitos dos extratos aquosos de $B$. trimera e $B$. 
TABELA 1. Espécies, populações, estádios de desenvolvimento, tratamentos e número total de células analisadas no ciclo celular (interfase, prófase, metáfase, anáfase, telófase) de pontas de raízes de Allium cepa tratadas com os extratos aquosos de $B$. trimera e $B$. articulata.

\begin{tabular}{|c|c|c|c|c|c|}
\hline $\begin{array}{c}\text { Espécie - População- } \\
\text { Estádio }\end{array}$ & Tratamento & $\begin{array}{l}\text { Número Total } \\
\text { de Células }\end{array}$ & $\begin{array}{l}\text { № de Células } \\
\text { em Interfase }\end{array}$ & $\begin{array}{l}\text { № de células } \\
\text { em Divisão }\end{array}$ & $\begin{array}{c}\text { Índice } \\
\text { Mitótico (\%) }\end{array}$ \\
\hline \multirow{3}{*}{$\begin{array}{c}\text { Baccharis trimera- } \\
\text { População } 1 \text { - Reprodutivo }\end{array}$} & Controle & 4000 & 3748 & 252 & $6,3 a$ \\
\hline & $15 \mathrm{~g} \mathrm{~L}^{-1}$ & 4000 & 3939 & 61 & $1,525 b$ \\
\hline & $75 \mathrm{~g} \mathrm{~L}^{-1}$ & 4000 & 3912 & 88 & $2,2 b$ \\
\hline \multirow{3}{*}{$\begin{array}{c}\text { Baccharis trimera- } \\
\text { População } 1 \text { - Vegetativo }\end{array}$} & Controle & 4000 & 3756 & 244 & $6,1 \mathrm{a}$ \\
\hline & $15 \mathrm{~g} \mathrm{~L}^{-1}$ & 4000 & 3995 & 5 & $0,125 b$ \\
\hline & $75 \mathrm{~g} \mathrm{~L}^{-1}$ & 4000 & 3916 & 84 & $2,1 c$ \\
\hline \multirow{3}{*}{$\begin{array}{c}\text { Baccharis trimera- } \\
\text { População } 2 \text { - Reprodutivo }\end{array}$} & Controle & 4000 & 3767 & 233 & $5,825 a$ \\
\hline & $15 \mathrm{~g} \mathrm{~L}^{-1}$ & 4000 & 3990 & 10 & $0,25 b$ \\
\hline & $75 \mathrm{~g} \mathrm{~L}^{-1}$ & 4000 & 3985 & 15 & $0,375 b$ \\
\hline \multirow{3}{*}{$\begin{array}{c}\text { Baccharis trimera - } \\
\text { População } 2 \text { - Vegetativo }\end{array}$} & Controle & 4000 & 3791 & 209 & $5,225 a$ \\
\hline & $15 \mathrm{~g} \mathrm{~L}^{-1}$ & 4000 & 3992 & 8 & $0,2 b$ \\
\hline & $75 \mathrm{~g} \mathrm{~L}^{-1}$ & 4000 & 3979 & 21 & $0,525 b$ \\
\hline \multirow{3}{*}{$\begin{array}{c}\text { Baccharis articulata- } \\
\text { População } 1 \text { - Reprodutivo }\end{array}$} & Controle & 4000 & 3720 & 280 & $7 a$ \\
\hline & $15 \mathrm{~g} \mathrm{~L}^{-1}$ & 4000 & 3931 & 69 & $1,725 b$ \\
\hline & $75 \mathrm{~g} \mathrm{~L}^{-1}$ & 4000 & 3964 & 36 & $0,9 c$ \\
\hline \multirow{3}{*}{$\begin{array}{c}\text { Baccharis articulata - } \\
\text { População } 1 \text { - Vegetativo }\end{array}$} & Controle & 4000 & 3787 & 213 & $5,325 a$ \\
\hline & $15 \mathrm{~g} \mathrm{~L}^{-1}$ & 4000 & 3908 & 92 & $2,3 b$ \\
\hline & $75 \mathrm{~g} \mathrm{~L}^{-1}$ & 4000 & 3975 & 25 & $0,625 c$ \\
\hline \multirow{3}{*}{$\begin{array}{c}\text { Baccharis articulata - } \\
\text { População } 2 \text { - Reprodutivo }\end{array}$} & Controle & 4000 & 3743 & 257 & $6,425 a$ \\
\hline & $15 \mathrm{~g} \mathrm{~L}^{-1}$ & 4000 & 3923 & 77 & $1,925 b$ \\
\hline & $75 \mathrm{~g} \mathrm{~L}^{-1}$ & 4000 & 3913 & 87 & $2,175 b$ \\
\hline \multirow{3}{*}{$\begin{array}{c}\text { Baccharis articulata- } \\
\text { População } 2 \text { - Vegetativo }\end{array}$} & Controle & 4000 & 3763 & 237 & $5,925 a$ \\
\hline & $15 \mathrm{~g} \mathrm{~L}^{-1}$ & 4000 & 3896 & 104 & $2,6 b$ \\
\hline & $75 \mathrm{~g} \mathrm{~L}^{-1}$ & 4000 & 3918 & 82 & $2,05 b$ \\
\hline
\end{tabular}

Médias seguidas da mesma letra não diferem significativamente ao nível de $5 \%$, pelo teste $\chi^{2}$. 
TABELA2. Espécies, populações, estádios de desenvolvimento, tratamentos, número total de células analisadas, número de aberrações celulares e porcentagem de células aberrantes de pontas de raízes de Allium cepa tratadas com os extratos aquosos de $B$. trimera e $B$. articulata.

\begin{tabular}{|c|c|c|c|c|c|c|}
\hline \multirow{2}{*}{$\begin{array}{c}\text { Espécie - População } \\
\text { - Estádio }\end{array}$} & \multirow[t]{2}{*}{ Tratamento } & \multirow{2}{*}{$\begin{array}{l}\text { No total de } \\
\text { células } \\
\text { analisadas }\end{array}$} & \multicolumn{3}{|c|}{ Aberrações celulares } & \multirow{2}{*}{$\begin{array}{l}\text { Total de } \\
\text { células } \\
\text { aberrantes }\end{array}$} \\
\hline & & & $\begin{array}{l}\text { Pontes em } \\
\text { anáfase e } \\
\text { telófase }\end{array}$ & $\begin{array}{c}\text { Células } \\
\text { binucleadas }\end{array}$ & $\begin{array}{c}\text { Células } \\
\text { micronucleadas }\end{array}$ & \\
\hline \multirow{3}{*}{$\begin{array}{c}\text { Baccharis trimera - } \\
\text { População } 1 \text { - } \\
\text { Reprodutivo }\end{array}$} & Controle & 4000 & - & - & - & Oa \\
\hline & $15 \mathrm{~g} \mathrm{~L}^{-1}$ & 4000 & 1 & 29 & - & $30 b$ \\
\hline & $75 \mathrm{~g} \mathrm{~L}^{-1}$ & 4000 & 5 & 35 & 2 & $42 b$ \\
\hline \multirow{3}{*}{$\begin{array}{c}\text { Baccharis trimera - } \\
\text { População } 1 \text { - } \\
\text { Vegetativo }\end{array}$} & Controle & 4000 & - & - & - & Oa \\
\hline & $15 \mathrm{~g} \mathrm{~L}^{-1}$ & 4000 & - & 24 & 4 & $28 b$ \\
\hline & $75 \mathrm{~g} \mathrm{~L}^{-1}$ & 4000 & 8 & 18 & - & $26 b$ \\
\hline \multirow{3}{*}{$\begin{array}{c}\text { Baccharis trimera - } \\
\text { População } 2 \text { - } \\
\text { Reprodutivo }\end{array}$} & Controle & 4000 & - & - & - & $0 \mathrm{a}$ \\
\hline & $15 \mathrm{~g} \mathrm{~L}^{-1}$ & 4000 & - & 9 & - & $9 b$ \\
\hline & $75 \mathrm{~g} \mathrm{~L}^{-1}$ & 4000 & 7 & 58 & 1 & $66 c$ \\
\hline \multirow{3}{*}{$\begin{array}{c}\text { Baccharis trimera - } \\
\text { População } 2 \text { - } \\
\text { Vegetativo }\end{array}$} & Controle & 4000 & - & - & - & Oa \\
\hline & $15 \mathrm{~g} \mathrm{~L}^{-1}$ & 4000 & - & 13 & - & $13 b$ \\
\hline & $75 \mathrm{~g} \mathrm{~L}^{-1}$ & 4000 & 7 & 61 & - & $68 c$ \\
\hline \multirow{3}{*}{$\begin{array}{c}\text { Baccharis articulata - } \\
\text { População 1 - } \\
\text { Reprodutivo }\end{array}$} & Controle & 4000 & - & - & - & Oa \\
\hline & $15 \mathrm{~g} \mathrm{~L}^{-1}$ & 4000 & 6 & 26 & - & $32 b$ \\
\hline & $75 \mathrm{~g} \mathrm{~L}^{-1}$ & 4000 & 1 & - & - & $1 \mathrm{c}$ \\
\hline \multirow{3}{*}{$\begin{array}{c}\text { Baccharis articulata - } \\
\text { População } 1 \text { - } \\
\text { Vegetativo }\end{array}$} & Controle & 4000 & - & - & - & Oa \\
\hline & $15 \mathrm{~g} \mathrm{~L}^{-1}$ & 4000 & 3 & 16 & - & $19 b$ \\
\hline & $75 \mathrm{~g} \mathrm{~L}^{-1}$ & 4000 & 1 & 8 & - & $9 b$ \\
\hline \multirow{3}{*}{$\begin{array}{c}\text { Baccharis articulata - } \\
\text { População } 2 \text { - } \\
\text { Reprodutivo }\end{array}$} & Controle & 4000 & - & - & - & Oa \\
\hline & $15 \mathrm{~g} \mathrm{~L}^{-1}$ & 4000 & 5 & 16 & - & $21 b$ \\
\hline & $75 \mathrm{~g} \mathrm{~L}^{-1}$ & 4000 & 15 & 11 & - & $26 b$ \\
\hline \multirow{3}{*}{$\begin{array}{c}\text { Baccharis articulata - } \\
\text { População } 2 \text { - } \\
\text { Vegetativo }\end{array}$} & Controle & 4000 & - & - & - & Oa \\
\hline & $15 \mathrm{~g} \mathrm{~L}^{-1}$ & 4000 & 19 & 24 & - & $43 b$ \\
\hline & $75 \mathrm{~g} \mathrm{~L}^{-1}$ & 4000 & 13 & 8 & - & $21 c$ \\
\hline
\end{tabular}

Médias seguidas da mesma letra não diferem significativamente ao nível de $5 \%$, pelo teste $\chi^{2}$. 

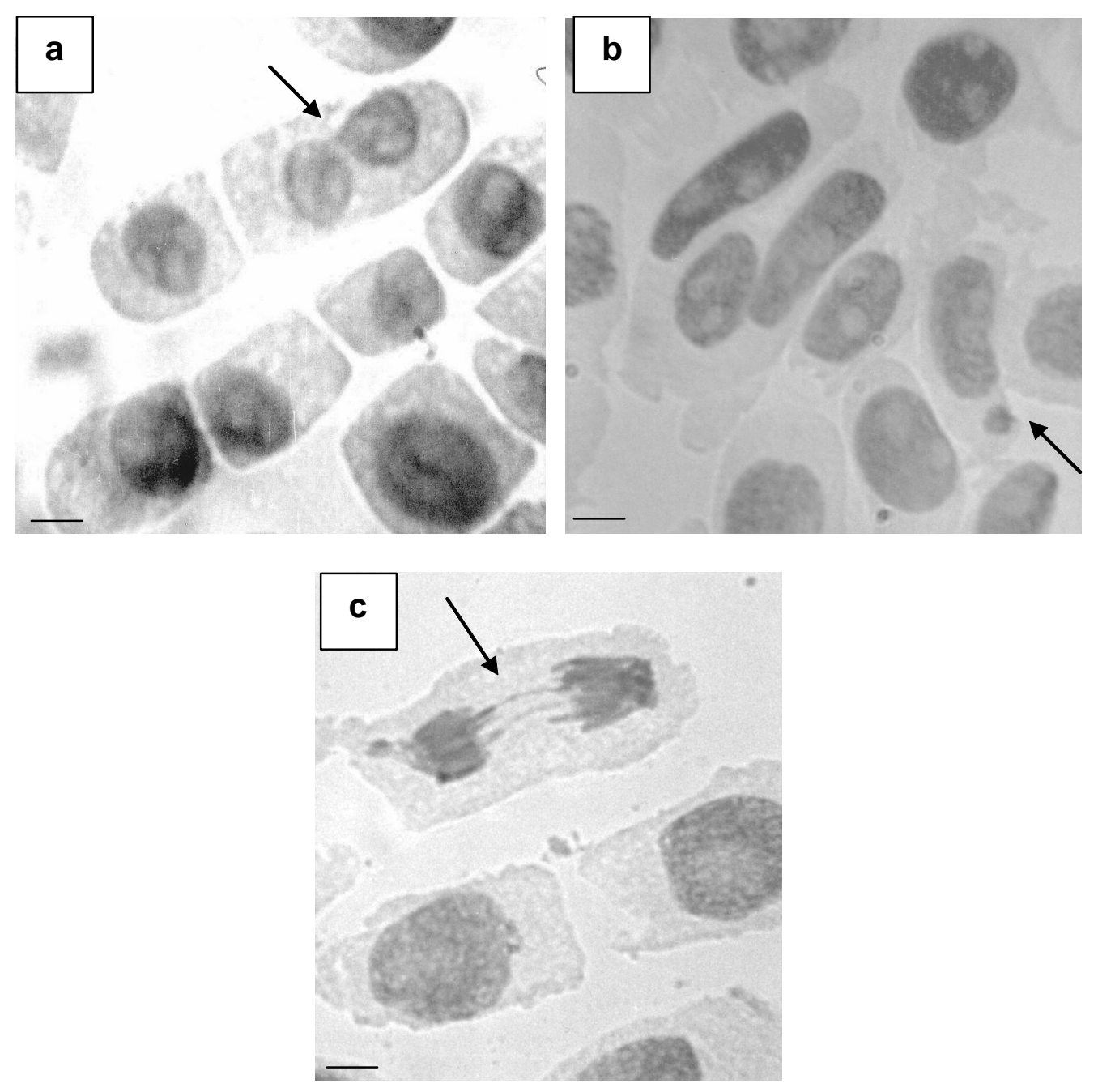

FIGURA 1. Células de Allium cepa submetidas aos extratos de $B$. trimera e $B$. articulata. a- seta indicando célula binucleada; $\mathbf{b}$ - seta indicando micronúcleo; $\mathbf{c}$ - seta indicando pontes em anáfase. Escala $10 \mu \mathrm{m}$.

articulata. Em nosso estudo, foram utilizados extratos aquosos brutos obtidos por decocção, visto que a população humana utiliza-os sob esta forma. Os testes de citotoxicidade utilizando sistema teste vegetal in vivo, como o de Allium cepa, estão validados por vários pesquisadores que realizam de forma conjunta teste animal in vitro e os resultados obtidos são similares (Teixeira et al., 2003; Vicentini et al., 2001).

Neste estudo, extratos aquosos de B. trimera e $B$. articulata apresentaram inibição da divisão celular já na concentração usual de $15 \mathrm{mg} \mathrm{mL}^{-1}$ (Tabela 1), bem como alterações celulares (Tabela 2), indicando a ocorrência de atividade antiproliferativa e mutagênica dos extratos. Esses resultados estão em acordo com os estudos realizados por Pinho et al. (2005a, 2005b), que avaliaram os extratos aquosos da espécie $B$. trimera através do sistema teste vegetal de Allium cepa e teste de linfócitos de sangue periférico humano. Estes autores observaram atividade antiproliferativa e mutagênica dos extratos nas concentrações de $20 \mathrm{mg} \mathrm{mL}^{-1}$ e $200 \mathrm{mg} \mathrm{mL}^{-1}$, sendo encontrados nos dois estudos aberrações celulares semelhantes às obtidas neste trabalho. Além disso, Borgo et al. (2004) demonstraram haver atividade mutagênica dos extratos aquosos de $B$. articulata através do ensaio Salmonella/Microssoma.

Estes resultados reforçam importância do sistema teste de Allium cepa, já que o mesmo apresenta resultados similares aos obtidos com outros sistemas testes. Segundo Fikejö (1994), mesmo que o metabolismo vegetal seja diferente, o sistema teste de Allium cepa é um excelente parâmetro de análise citotóxica, além de que a observação da ocorrência de alterações cromossômicas no ciclo celular de $A$. cepa tem sido usada como indicativo para prevenir a população humana sobre o consumo do produto (Vicentini et al., 2001). De acordo com Craag \& Newman (2005), muitos dos agentes utilizados na terapia do câncer 
são derivados de fontes naturais e foram descobertos a partir de testes de citotoxicidade, por inibirem a proliferação de células cancerosas em modelos in vitro ou in vitro.

As espécies B. trimera e B. articulata contém taninos e flavonóides dentre outras substâncias em sua composição química. A atividade enzimática associada aos taninos pode ser responsável pela inibição da divisão celular de Allium cepa (Teixeira et al., 2003). Estas espécies também contêm flavonóides, os quais têm demonstrado possuir atividade citotóxica (Ya-Qin et al., 2001). Os flavonóides de Humulus lupulus L. e Lonchocarpus spp. apresentaram atividade citotóxica e antiproliferativa sob o ciclo celular de células cancerosas da próstata (Delmulle et al., 2006; Borges-Argáez et al., 2007). Outras espécies medicinais, que possuem taninos e flavonóides em sua constituição, como Pterocaulon polystachyum e Achyrocline satureidoides têm sido estudadas através do sistema teste de Allium cepa, e os resultados indicam a presença de atividade antiproliferativa nestes extratos (Knoll et al., 2006; Fachinetto et al., 2007).

Apesar das espécies vegetais apresentarem uma possível modificação de seus constituintes em razão de seu estádio de desenvolvimento, em nosso estudo, não foram observadas diferenças significativas na atividade antiproliferativa e mutagênica que pudessem estar associadas ao estádio em que se encontravam.

Através de nossos resultados, é possível verificar-se a presença de atividade antiproliferativa e mutagênica das espécies estudadas, indicando que sua utilização pela população requer maior cuidado. No entanto, são necessários mais estudos para avaliar com maior precisão os riscos potenciais dos agentes mutagênicos presentes nos extratos aquosos de $B$. trimera e $B$. articulata.

\section{REFERÊNCIA}

ALONSO, J.R. Tratado de fitomedicina: bases y clinicas farmacológicas. Buenos Aires: Isis, 1998. p.350-4.

AYRES, M. Bioestat 3.0: aplicações estatísticas nas áreas das ciências biológicas e médicas. Belém: Sociedade Civil Mamirauá, Brasília: CNPq, 2003. 290p. BORGES-ARGÁEZ, R. et al. Cytotoxic and antiprotozoal activity of flavonoids from Lonchocarpus spp. Phytomedicine, v.14, p.530-3, 2007.

BORGO, J.; ROSA, D.P.; VARGAS, V.M.F. Mutagenicidade do extrato aquoso de Baccharis articulata (Lam.) Persoon no ensaio Salmonella/Microssoma. Revista Brasileira de Toxicologia, v.17, p.37-43, 2004.

CABRERA, G.L.; RODRIGUEZ, D.M.G. Genotoxicity of soil from farmland irrigated with wastewater using three plant bioassays. Mutation Research-Fundamental and Molecular Mechanisms of Mutagenesis, v.426, p.2114, 1999.
CAMPAROTO, M.L. et al. Effects of Maytenus ilicifolia Mart. and Bauhinia candicans Benth infusions on onion roottip and rat bone-marrow cells. Genetics and Molecular Biology, v.25, p.85-9, 2002.

CASTRO, H.G. et al. Rendimento de tanino em dois acessos de carqueja (Baccharis myriocephala DC.), em diferentes épocas de colheita em Viçosa MG. Revista Brasileira de Plantas Medicinais, v.1, p.29-33, 1999.

CRAAG, G.M.; NEWMAN, D.J. Plants as source of anticancer agents. Journal of Ethnopharmacology, v.100, p.72-9, 2005.

DELMULLE, L. et al. Anti-proliferative properties of prenylated flavonoids from hops (Humulus lupulus L.) in human prostate cancer cell lines. Phytomedicine, v.13, p.732-4, 2006.

DE MELLO, J.; PETROVICK, P.R. Quality control of Baccharis trimera (Less.) DC. (Asteraceae) hydroalcoholic extracts. Acta Farmacéutica Bonaerense, v.19, n.3, p.211-5, 2000.

DI STASI, L.C. et al. Screening in mice of some medicinal plants used for analgesic purposes in the state of São Paulo. Journal of Ethnopharmacology, v.24, p.205-11, 1988.

DUKE, J.A. Toxins: their toxicity and distribution in plant genera. In: Handbook of medicinal herbs. Boca Raton: CRC Press, 2000. p.525-68.

FACHINETTO, J.M. et al. Anti-proliferative effect of infusions of Achyrocline satureioides on the Allium cepa cell cycle. Brazilian Journal of Pharmacognosy, v.17, p.49-54, 2007.

FARMACOPÉIADOS ESTADOS UNIDOS DO BRASIL. São Paulo: Siqueira, 1959. 1254p.

FIKEJÖ, G. Allium Test II: Assesmente of chemical's genotoxic potential by recording aberrations in chromosomes and cell divisions in root tips of Allium cepa L. Environmental Toxicology and Water Quality, v.9, p.235-41, 1994.

GADANO, A. et al. In vitro genotoxic evaluation of the medicinal plant Chenopodium ambrosioides L. Journal of Ethnopharmacology, v.81, p.11-6, 2002.

GIANIELLO, J.C.; GIORDANO, O.S. Barticulidiol, um nuevo furano diterpeno aislado de Baccharis articulata Lam. (Persoon). Revista Latinoamericana de Química, v.13, p.76-8, 1982.

GUERRA, M.; SOUZA, M.J. Como observar cromossomos: um guia de técnicas em citogenética vegetal, animal e humana. Ribeirão Preto: FUNPEC, 2002. 191p.

JARVIS, B.B. et al. Trichothecene mycotoxins from Brazilian Baccharis species. Phytochemistry, v.30, p.789-97, 1991.

KNOLL, M.F. et al. Effects of Pterocaulon polystachyum DC. (Asteraceae) on onion (Allium cepa) root-tip cells. Genetics and Molecular Biology, v.29, p.539-42, 2006. KUROYANAGI, M. et al. Studies on the constituents of Baccharis genistelloides. Chemical and Pharmaceutical Bulletin, v.33, n.33, p.5075-8, 1985.

NEWMAN, D.J.; CRAGG, G.M.; SNADER, K.M. Natural products as sources of new drugs over the period 19812002. Journal of Natural Products, v.66, p.1022-37, 2003.

PAULSEN, E. Contact sensitization from Compositae containing herbal remedies and cosmetics. Contact Dermatitis, v.47, p.189-98, 2002. 
PINHO, D.D.S. et al. Investigação da genotoxicidade na medicina popular: o chá de carqueja (Baccharis trimera). In: CONGRESSO BRASILEIRO DE GENÉTICA, 51., 2005, Águas de Lindóia. Resumos... Ribeirão Preto: Sociedade Brasileira de Genética, 2005a. p.1207.

PINHO, D.D.S. et al. Avaliação da mutagenicidade de carqueja (Baccharis trimera) em teste de linfócitos de sangue periférico humano. In: CONGRESSO DE INICIAÇÃO CIENTÍFICA, 14., 2005, Pelotas. Resumos... Pelotas: UCPEL, 2005b. p.1360-3.

SANTOS, C.A.M.; TORRES, K.R.; LEONART, R. Plantas medicinais herbarium, flora et scientia. 2.ed. São Paulo: Ícone, 1988. 160p.

SILVA, C.R. et al. Absence of mutagenic and citotoxic potentiality of senna (Cassia angustifolia Vahl.) evaluated by microbiological tests. Revista Brasileira de Farmacognosia, v.14, p.1-3, 2004.

SIMÕES, C.M.O. et al. Plantas da medicina popular no Rio Grande do Sul. Porto Alegre: UFRGS. 1986. 186p. SIMÕES-PIRES, C.A. et al. Análise da composição química do óleo essencial de três espécies do gênero Baccharis coletadas no rio Grande do Sul. 2002. Disponível em: <http://www.plantasmedicinales.org>. Acesso em: 18 set. 2009.

SIQUEIRA, N.C.S. et al. Análise comparativa dos óleos essenciais de Baccharis articulata (Lam) Pers. e Baccharis trimera (Less.) DC. (Compositae), espécies espontâneas no Rio Grande do Sul. Revista Brasileira de Farmácia, v.3, p.36-9, 1985.

SIQUEIRA, N.C.D.; ALICE, C.B.; THIENSEN, F.V. Aspectos farmacognósticos e perfil cromatográfico dos constituintes de Baccharis articulata (Lam.) Pers. Compositae. Caderno de Farmácia, v.4, p.63-76, 1988. SOICKE, H.; LENG-PESCHLOW, E. Characterization of flavonoids from Baccharis trimera and their antihepatotoxic properties. Planta Medica, v.53. p.37-9, 1987.

SOUSA, M.P. et al. Constituintes químicos de plantas medicinais brasileiras. Fortaleza: Editora UFC, 1991. 416p.

TEIXEIRA, R.O. et al. Assessment of two medicinal plants, Psidium guajava $\mathrm{L}$. and Achillea millefolium $\mathrm{L}$. in in vivo assays. Genetics and Molecular Biology, v.26, p.551-5, 2003.

VICENTINI, V.E.P. et al. Averrhoa carambola L., Syzygium cumini (L.) Skeels and Cissus sicyoides L.: medicinal herbal tea effects on vegetal and test systems. Acta Scientiarum, v.23, p.593-8, 2001.

YA-QIN, S. et al. Cytotoxic flavonoids with isoprenoids groups from Morus mongolica. Journal of Natural Products, v.64, p.181-8, 2001.

ZDERO, C.; BOHLMANN, F.; NIEMEYER, H.M. An unusual dimeric sesquiterpene and other constituents from Chilean Baccharis species. Phytochemystry, v.30, p.597-601, 1991. 